F. Reprod. Fert. (1974) 36, 23-28

\title{
EARLY HISTOLOGICAL CHANGES IN EXPERIMENTAL CONTRALATERAL EPIDIDYMO- ORCHITIS IN THE RABBIT
}

\author{
E. ZAPPI AND S. SHULMAN \\ Department of Microbiology, New York Medical College, \\ New York, N.Y. 10029, U.S.A.
}

(Received 13th December 1972)

\begin{abstract}
Summary. Histological changes in the left gonad are described for a group of ten male rabbits submitted to a cryo-injury of the right testis between $6 \mathrm{hr}$ and 4 days earlier. Striking changes in the content of the ductus epididymidis were observed in all the animals. These changes are regarded as non-specific responses of the host to the physical trauma.

Eight of the ten rabbits also presented modifications of the germinal epithelium and the interstitial spaces which seemed to represent the initial stages of the contralateral lesion observed in a larger group of animals killed between 1 and 4 weeks afterwards, in which the right testis was also submitted to the same experimental lesion. The changes are appraised as the morphological expression of an autoallergic reaction in response to the cryo-injury of an organ that has autoantigenic properties.
\end{abstract}

\section{INTRODUCTION}

In a previous study, the condition of 'contralateral epididymo-orchitis' (CEO) was described (Zappi, Nemirovsky \& Shulman, 1973). This condition was experimentally induced in the rabbit by an intensive freezing injury of the contralateral gonad.

The principal histopathological features of CEO were degenerative-regenerative changes in the germinal epithelium, vascular congestion, oedema, fibroproliferation, and mononuclear cell infiltration. An autoallergic aetiology was tentatively proposed for the condition analogous to the process induced in the guinea-pig, the rat, and other animals by the injection of testicular material and adjuvants (Eyquem \& Krieg, 1965; Shulman \& Zappi, 1973).

In an attempt to determine the time sequence and to gain more insight into the pathogenesis of CEO, interest in the present study was focused on the earliest histological changes, i.e. those occurring between $6 \mathrm{hr}$ and 4 days after the injury had been inflicted on the target testis.

\section{MATERIALS AND METHODS}

Ten adult male New Zealand White rabbits with an initial body weight of about $3.0 \mathrm{~kg}$ were submitted to a standard cryo-injury of the right testis that 


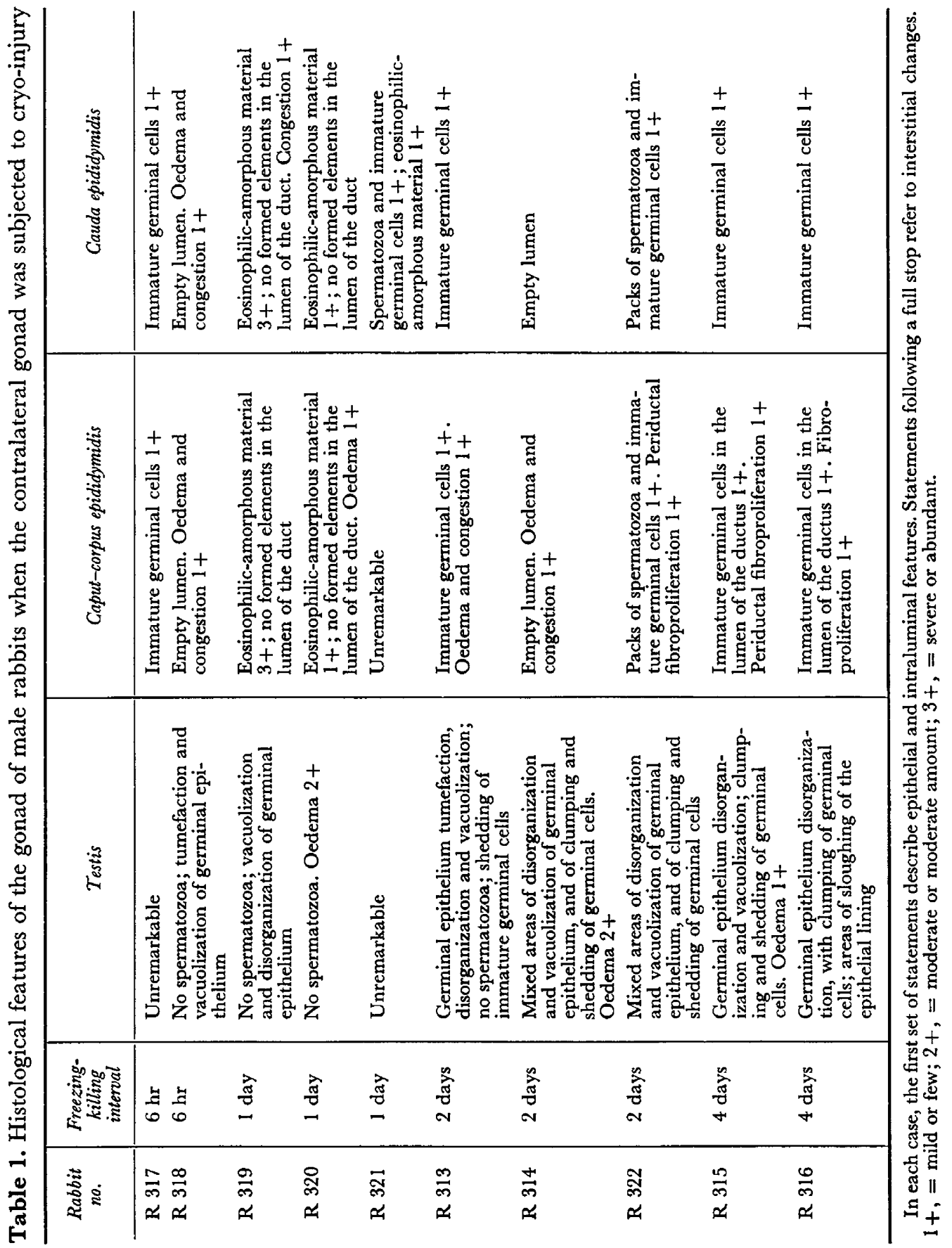


produced acute necrosis of $0.5 \mathrm{~cm}^{3}$ of parenchyma (Zappi \& Shulman, 1971). The animals were killed at various intervals between $6 \mathrm{hr}$ and 4 days after cryo-injury (Table 1).

The cryosurgical equipment consisted of the Linde CE 2 unit and the PR-2 cryoprobe (Barron, 1971). The surgical approach to the rabbit gonad has already been described by Zappi \& Shulman (1972).

Immediately after the animals were killed, their gonads were removed, fixed in Bouin's solution and embedded in paraffin wax. Sections $(5 \mu \mathrm{m})$ were prepared from each organ, including the equatorial region and the superior and inferior poles of the testis, with portions of the attached caput and cauda epididymidis. The sections were mounted on slides and stained with haematoxylin-eosin.

Subdivision of the rabbit epididymis into caput-corpus and cauda epididymidis was based primarily on the periductal muscular system, which is strongly developed in the latter section, but almost absent from the former.

\section{RESULTS}

The histological changes observed in the gonad contralateral to the one which was injured in rabbits treated in this experiment are summarized in Table 1. For comparative purposes, some histological pictures obtained from rabbits belonging to the first series that was reported in connection with CEO (PI. 1, Fig. 4, and Pl. 2, Fig. 12), as well as others from normal rabbits (Pl. 1, Fig. 2 and Pl. 2, Fig. 8) are presented.

Plate 1, Fig. 1 demonstrates the acute epididymal changes seen in two animals ( $R 317$ and R 318) examined $6 \mathrm{hr}$ after cryo-injury. The dense packs of mature sperm cells normally seen in the lumen of the ductus (P1. 1, Fig. 2) were partly replaced by immature germinal cells, free or mixed with homogeneous eosinophilic material. In addition, there were quite marked alterations in the germinal epithelium of R 318 (Table 1).

Of the changes detected in the three animals studied 1 day after cryosurgery, those shown by one of them (R 321) only affected the epididymal contents (Pl. 1, Fig. 3). The other two animals (R 319 and R 320) also showed changes in the germinal epithelium, as well as mild interstitial oedema (Table 1). The interstitial oedema, however, had a more protracted development and it was only severe in some of the animals studied 1 or more weeks after cryo-injury (Pl. 1, Fig. 4).

Two days after surgery, all the animals ( $\mathbf{R} 313, \mathbf{R} 314, \mathbf{R} 322$ ) exhibited significant modifications of the germinal epithelium (Pl. 1, Figs 5 and 6 and Pl. 2, Fig. 7), besides epididymal changes (Table 1). These changes may be regarded as earlier expressions of the same destructive process that later leads to the extensive denudation of the seminiferous tubules observed in some of the animals of the earlier reported series (see Pl. 1, Fig. 4).

Both animals killed 4 days after surgery ( $R 315$ and $R 316$ ) provided evidence of how the destructive process reached an end-point with the elimination of the damaged epithelium (Pl. 2, Figs 9 and 10). 
Sections from the two animals killed 4 days after freezing exhibited some degree of fibroproliferation (Pl. 2, Fig. 11). This reaction was seen to be much more developed 2 weeks after cryo-injury (Pl. 2, Fig. 12).

\section{DISGUSSION}

A constant feature in the left, intact gonad of the animals and the earliest one, since it was noted $6 \mathrm{hr}$ after cryo-injury of the right testis, was a change in the content of the ductus epididymidis. This structure, which was normally filled with thick bundles of mature sperm cells, appeared empty, or, if longer periods intervened between the injury and histological observation, isolated or clumped immature germinal cells were visible in the lumen, mixed with an amorphous, eosinophilic material not present there under normal conditions. These changes were frequently followed by others which proceeded in a stepwise fashion, consisting of (a) disappearance of mature sperm cells from the seminiferous tubule, along with tumefaction, disorganization, and vacuolization of the germinal epithelium; (b) clumping of immature germinal cells and shedding of these conglomerates in the lumen of the seminiferous tubules; and (c) variable denuding of the wall of the seminiferous tubules, according to the more or less intensive damage suffered by the germinal epithelium. The modifications in the seminiferous tubules were accompanied by mild to moderate interstitial vascular stasis and oedema in the testis as well as in the epididymis. In some of the animals examined 4 days after inflicting the lesion, a fibroblastic proliferation had begun to evolve in the interstitial fluid which had collected in the cauda epididymidis.

The early and constant nature of the changes in the epididymal content is taken as an indication that the changes may result from a non-specific response

\section{EXPLANATION OF PLATE 1}

FIG. 1. Caput-corpus epididymidis from rabbit (R 318) $6 \mathrm{hr}$ after cryo-injury to the contralateral testis. A few immature germinal cells and thick eosinophilic amorphous material are visible in the lumen of the tubules (cross-sections on top and on the bottom, respectively), instead of the normal content of mature sperm cells. There is moderate interstitial oedema. Compare with Fig. 2. H \& E. $\times 100$.

Fig. 2. Normal rabbit caput-corpus epididymidis. Note the thick packs of mature spermatozoa in the lumen of the tubules-also present as a normal feature at the level of the cauda epididymidis - and the sparse collagen fibres in the interstitial space. H \& E. $\times 100$.

Fic. 3. Cauda epididymidis from rabbit (R 321) 1 day after cryo-injury to the contralateral testis. Abundant immature germinal cells of various types, mixed with particles of amorphous material, are visible in the lumen of the duct. Compare with Fig. 2. H \& E. $\times 100$.

FIG. 4. Testis parenchyma from rabbit ( $R$ 248) 1 week after cryo-injury to the contralateral cauda epididymidis. Severe interstitial oedema is present, with extensive destruction of the seminiferous tubules (on top), vasa recta (centre), and rete testis (to the right). H \& E. $\times 100$.

Frg. 5. Testis parenchyma from rabbit (R 322) 2 days after cryo-injury to the contraIateral testis. Note the area of moderate damage of germinal epithelium with vacuolization and shedding of clumped immature germinal cells. $\mathrm{H} \& \mathrm{E} . \times 100$.

Frg. 6. Seminiferous tubule from rabbit ( $R$ 314), longitudinal section 2 days after cryoinjury to the contralateral testis. There is disorganization and tumefaction of the germinal epithelium, shrinkage of the basal membrane, disarrangement of the cellular elements with loss of cellular limits, nuclear alterations, and obliteration of the tubular lumen. Compare with Fig. 8. H \& E. $\times 400$. 
P[. \TE; ]

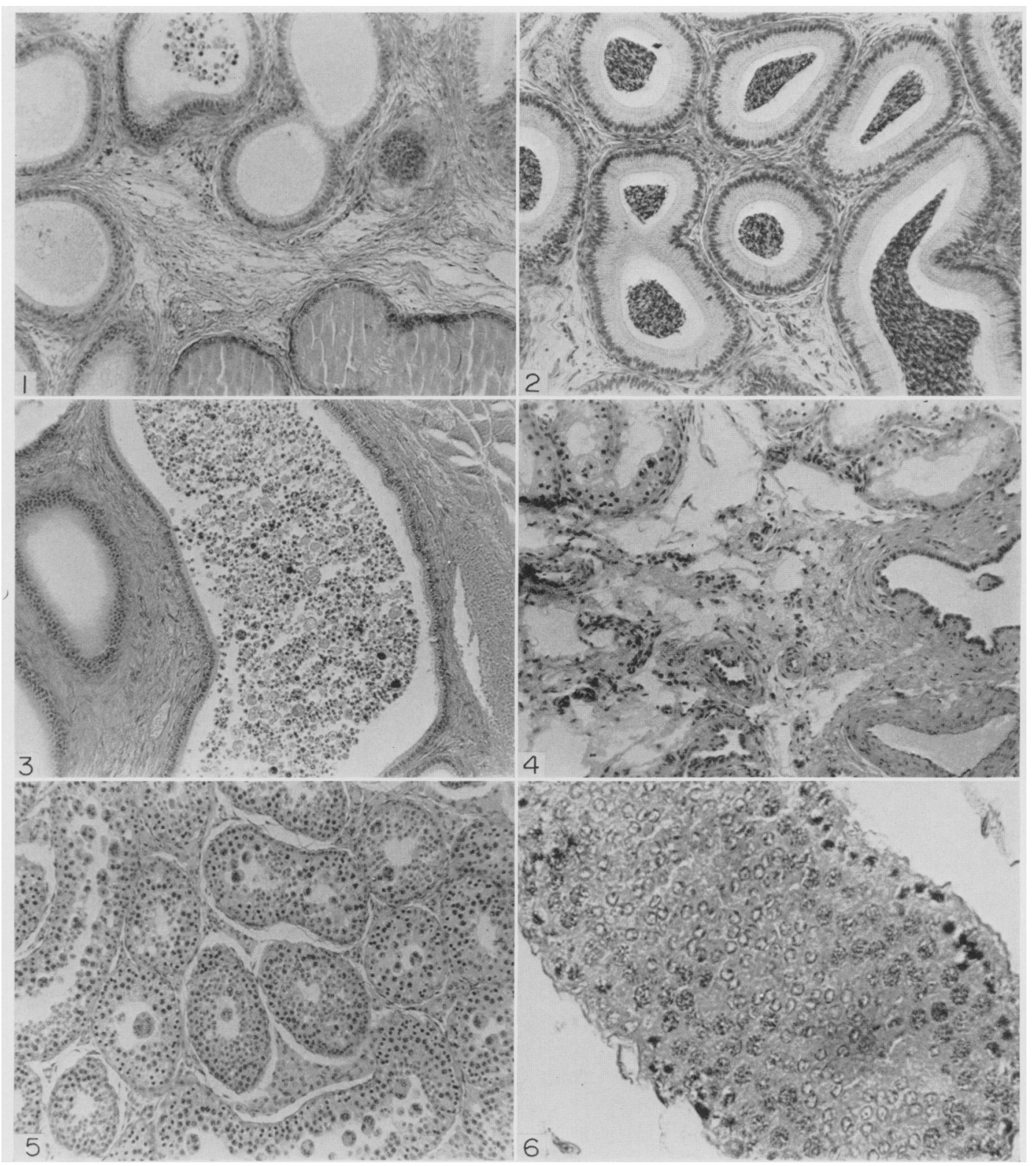




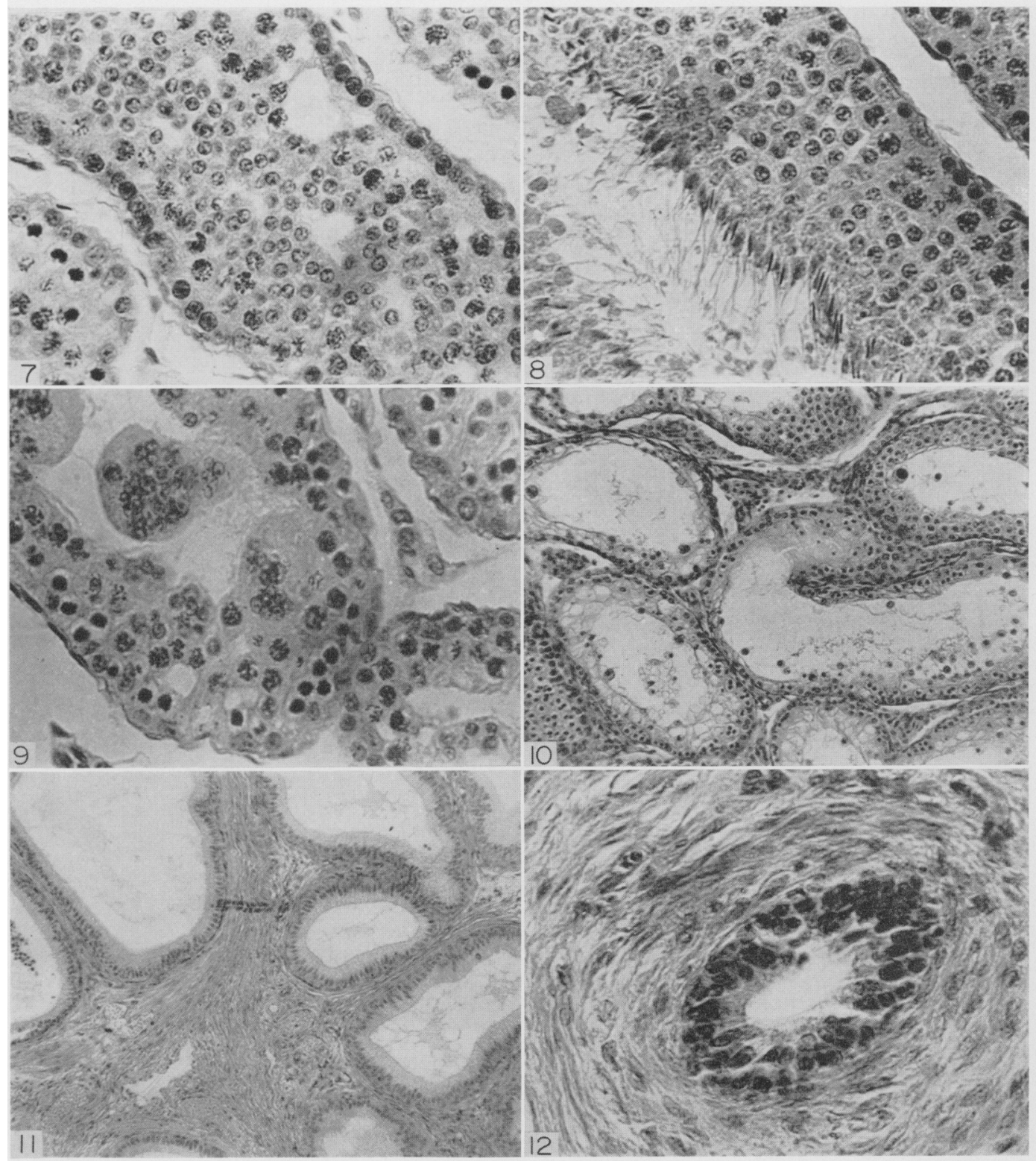


of the host to the trauma, probably in the form of a reflex contraction of the periductal muscular system.

The delayed, progressive and less uniform modifications seen in the germinal epithelium and in the interstitial spaces clearly represent the first stages in the development of CEO, and it may be assumed that these modifications have the same pathogenic mechanism proposed elsewhere for CEO, i.e. that derived from a predominantly cellular, autoimmune reaction. This hypothesis has been further elaborated on an experimental basis (E. Zappi, M. Nemirovsky and S. Shulman, in preparation).

The histological observations presented here confirm and complete the description of a new experimental model of an epididymo-orchitis with a possible autoallergic basis. They also demonstrate how readily and intensively one gonad may be affected by physical trauma to the contralateral one, even if both glands, as in the human species, are independently located in a completely extra-abdominal scrotum, and may throw light on the pathogenesis of some testicular conditions of unexplained origin.

\section{AGKNOWLEDGMENTS}

The technical assistance of Miss B. Flouton as well as the typing assistance of Mrs Z. Abrew are gratefully acknowledged. This work was supported by a research grant from The John A. Hartford Foundation, Inc.

\section{REFERENCES}

Barron, R. F. (1971) Cryoinstrumentation. In: Cryogenics in Surgery, p. 80. Eds. H. van Leden and W. G. Cahan. Medical Examination Publishing Co., Inc., New York.

EyQUeM, A. \& KRIEG, H. (1965) Experimental autosensitization of the testis. Ann. N.Y. Acad. Sci. 124, 270.

\section{EXPLANATION OF PLATE 2}

Frg. 7. Seminiferous tubules from rabbit (R 313), longitudinal section 2 days after cryoinjury to the contralateral testis. Note the vacuolization of the germinal epithelium and clumping of the immature germinal cells. Compare with Fig. 8. H \& E. $\times 400$.

Fig. 8. Normal rabbit seminiferous tubule, longitudinal section. Note the orderly disposition of the germinal cells, from the spermatogonia and Sertoli cells attached to the basal membrane to the mature spermatozoa, with their tails directed to the lumen of the tubule. The lumen of the tubule is free and the cellular boundaries are clearly recognizable. H \& E. $\times 400$.

FIG. 9. Seminiferous tubule from rabbit (R 315), oblique section 4 days after cryo-injury to the contralateral testis. Note severe damage of the germinal epithelium with clumping and shedding of immature germinal cells. Compare with Fig. 8. H \& E. $\times 400$.

FIG. 10. Testis parenchyma from rabbit (R 316) 4 days after cryo-injury to the contralateral gonad. Note area of devastated seminiferous tubules, sloughing of germinal epithelium, and increased interstitial cellularity. Compare with Fig. 5. H \& E. $\times 100$.

Fig. 11. Caput-corpus epididymidis from rabbit (R 316) 4 days after cryo-injury to the contralateral testis. There are a few immature germinal cells in the lumen of the dilated ductus. Note the severe interstitial oedema and mild fibroproliferation. Compare with Fig. 2. H \& E. $\times 100$.

FIG. 12. Caput-corpus epididymidis from rabbit (R 251) 2 weeks after cryo-injury to the contralateral caput-cauda epididymidis. Note the strong fibroproliferation and the tightening of the ductus. $\mathrm{H} \& \mathrm{E} . \times 400$. 
Shulman, S. \& ZaPPI, E. (1973) Cryo-immunization and the reproductive system: aspermatogenesis, orchitis and epididymitis. In: Second International Symposium on Immunology of Reproduction, Varna, Bulgaria, p. 75. Ed. K. Bratanov. Bulgarian Academy of Sciences, Sofia.

Zappi, E., Nemirovsky, M. \& Shulman, S. (1973) Contralateral epididymo-orchitis after cryo-injury to the male rabbit gonad. Immunology, 25, 891.

Zappi, E. \& Shulman, S. (1971) Cryo-immunization. The cold propagation in the target tissue and the resulting volume of the lesion. Cryobiology, 8, 235.

Zappi, E. \& Shulman, S. (1972) Cryo-immunology. Antibody response to epididymis freezing in the rabbit. Investve Urol. 10, 226. 